\title{
Estudos em Geografia Histórica e seu vínculo ao patrimônio-territorial
}

\author{
Adriano Bittencourt Andrade ${ }^{1}$
}

\begin{abstract}
Resumo: Este escrito apresenta a possibilidade de uso da Geografia Histórica como um instrumento para ativação do patrimônio-territorial. Busca, através de uma série de orientações metodológicas, iluminar dinâmicas territoriais de tempos pretéritos para visibilizar agentes de produção do espaço omitidos/esquecidos nos textos históricos, apresentando, numa microhistória, nuanças que revelem outros possíveis percursos socioespaciais. Sustentado em observações acumuladas por mais de uma década de estudos, pesquisas, bancas e escritos no campo da Geografia Histórica, apresenta-se de forma didática dez riscos ao se deparar com estudos nesse campo da Geografia, notadamente, no estabelecimento dos vínculos desta com o patrimônio material e imaterial.
\end{abstract}

Palavras-chave: Geografia histórica; cartografia histórica; patrimônio-territorial.

\section{Estudios de Geografía Histórica y su vínculo al patrimonio-territorial}

Resumen: Este escrito presenta la posibilidad de uso de la Geografía Histórica como un instrumento para la activación del patrimonio-territorial. A través de una serie de orientaciones metodológicas, iluminar dinámicas territoriales de tiempos pretéritos para identificar los agentes de producción del espacio olvidados en los textos históricos, presentando, en una microhistoria, matices que revelen otros posibles recorridos socioespaciales. En las observaciones acumuladas por más de una década de estudios, investigaciones, bancas y escritos en el campo de la Geografía Histórica, se presenta de forma didáctica diez riesgos al encontrarse con estudios en ese campo de la Geografía, especialmente, en el establecimiento de los vínculos de ésta con el patrimonio material e inmaterial.

Palabras-clave: Geografía Histórica; patrimonio-territorial; cartografía histórica.

\section{Researches in Historical Geography and their link to territorial-patrimony}

\begin{abstract}
This article presents the possibility of using Historical Geography as an instrument for activating territorial-patrimony. Through a group of methodological orientations, it goal shows the territorial dynamics of past times and identify the agents of space production omitted / forgotten in the historical texts, presenting, in a micro history, signals that reveal other possible socio-spatial ways. Supported on observations and analyses for more than a decade of studies, research, newsstands and writings about Historical Geography, ten main ideas are presented in a didactic way for this kind of studies, especially in the establishment of its link with patrimony.
\end{abstract}

Keywords: Historical Geography; territorial-patrimony; historical cartography.

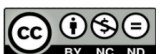

DOI: https://doi.org/10.26512/patryter.v4i7.27406

Como citar este artigo: Andrade, A. B. (2021). Estudos em Geografia Histórica e seu vínculo ao patrimônioterritorial. PatryTer - Revista Latinoamericana e Caribenha de Geografia e Humanidades, 4 (7), 63-77. DOI: https://doi.org/10.26512/patryter.v4i7.27406

Recebido: 05 de setembro de 2019. Aceite: 16 de março de 2020. Publicado: 01 de março de 2021.

${ }^{1}$ Doutor em Arquitetura e Urbanismo pela UFBA, Professor federal do Ministério da Defesa / CMB. ORCID: https://orcid.org/0000-0003-2176-5427. E-mail: abittandrade@gmail.com 


\section{Introdução}

Houve, nas últimas décadas, um significativo aumento da produção acadêmica brasileira, seja pela expansão quantitativa dos cursos de graduação e pós (MEC, 2019), seja pela competitividade $\mathrm{e}$ indução às publicações pelo mercado e instituições de fomento. No bojo desse volume estão os cursos de Geografia (Bauzys \& Ribeiro, 2015)" e, com eles, os trabalhos voltados para o campo da Geografia Histórica que abundam em eventos científicos e aparecem como tal em monografias, dissertações e teses.

A participação ativa nesse período de ampliação de trabalhos vinculados à Geografia Histórica (estudos de mestrado, doutoramento e pós-doutoramento, além da observação e análise de trabalhos acadêmicos na composição de bancas de avaliação) permite inferir que a maior quantidade veio acompanhada com algumas fragilidades qualitativas e equívocos que se repetem em diversos trabalhos analisados.

Essa problemática foi o contexto indutor da produção deste artigo, que se soma a outros escritos que discutem teórica e metodologicamente os caminhos da Geografia Histórica, a exemplo de Vasconcelos (1999), Abreu (2002 e 2011), Moraes (2009) e Andrade (2013). No caso do texto aqui posto, além de apresentar riscos recorrentes nos estudos afins à área, procura-se vincular a Geografia Histórica ao processo corrente de patrimonialização, identificando possibilidades de usar o seu instrumental para ativação popular do patrimônio-territorial.

Vislumbra-se, nesse sentido, a pesquisa científica como produto para a intervenção social. Busca-se assim, através de uma série de orientações metodológicas, possibilitar que, para além da descrição de objetos do espaço, as dinâmicas territoriais de tempos pretéritos sejam iluminadas, visibilizando os agentes de produção do espaço omitidos/esquecidos nos textos históricos. Objetiva-se, dessa forma, apresentar, numa microhistória (Lepetit, 2001), nuanças que revelem outros possíveis percursos socioespaciais e vivifique a Geografia como uma ciência social que ontologicamente se sustenta na capacidade explicativa de entender o mundo a partir da dinâmica dos territórios e como eles são produzidos e usados pelos homens.

Ratifica-se, então, que o objetivo geral que norteia o artigo é analisar pressupostos para estudos de Geografia Histórica vinculando esse campo da Geografia como instrumental para a ativação do patrimônio-territorial. Rompe-se assim com uma perspectiva habitual de naturalização do patrimônio material e imaterial e se propõe utilizar das possibilidades interpretativas de dinâmicas territoriais pretéritas como "máquina de guerra" . para vislumbrar outros arranjos territoriais e atores que apresentem patrimônios obliterados ou secundarizados pela perspectiva de "eleição" pontual de determinados espaços, monumentos ou práticas sociais para comporem o elenco de patrimônios na nossa atualidade.

Tem-se ainda como objetivos específicos: (1) apresentar orientações metodológicas que evitem equívocos recorrentes nos estudos de Geografia Histórica; (2) destacar o papel da cartografia histórica como instrumento fundamental para a interpretação de arranjos territoriais do passado visto que apresenta, medidas as ressalvas técnicas e de intencionalidade, marcos representativos (simbólicos e concretos) da história de um dado espaço; (3) estabelecer parâmetros que possibilitem que os estudos da Geografia Histórica "toquem" criticamente o tempo presente, rompendo assim com as abordagens meramente descritivas de arranjos espaciais do passado.

Metodologicamente, a produção do texto deriva de uma longa pesquisa bibliográfica e embate teórico com outros autores. O escrito que aqui se apresenta é resultado concreto do aprofundamento dos debates desenvolvidos no "III Seminário Latinoamericano: Imagen y representaciones espaciales. Perspectivas geográficas" que aconteceu abril de 2019 na UNAM (Universidade Nacional Autónoma de México) e foi materializado na publicação do terceiro número da revista PatryTer (Andrade \& Andrade, 2019). Sustenta-se então, em análises prévias (participação de bancas de mestrado e doutorado, diálogo com outros autores e aplicação empírica dos constructos desse ramo disciplinar) e amadurecimento do resultado a partir de outros textos já submetidos aos pares.

A estrutura do texto perpassa pela discussão das dez seções relacionadas a seguir que demarcam pressupostos conceituais ou metodológicos para quem se propõe a fazer estudos no campo da Geografia Histórica e, no caso aqui discutido, vinculá-la à discussão patrimonial: (1) $O$ entendimento do espaço geográfico como totalidade multidimensional, para muito além de uma visão fragmentada do mesmo; (2) Os limites e possibilidades da pesquisa em fontes primárias; (3) Os riscos de anacronia no uso de terminologias e/ou conceitos; (4) As estratégias analíticas e metodológicas para avançar na pesquisa da Geografia Histórica quando houver lacunas de informação documental; (5) A identificação dos agentes de produção do espaço e seus respectivos 
interesses, entendendo a sua diferenciação no tempo e espaço; (6) Diante das incontáveis possibilidades de eventos num mesmo momento, deve-se considerar o texto histórico como uma tentativa interpretativa de um dado arranjo espaçotemporal; (7) O uso da cartografia histórica como instrumento de análise de paisagens pretéritas; (8) Atentar para os limites técnicos e intencionalidades presentes em cada fonte de pesquisa, notadamente para as cartográficas; (9) Explorar a diversidade de fontes como estratégia de cruzar informações em busca da inapreensível dinâmica espacial; (10) Não restringir os estudos de Geografia Histórica à mera descrição quantitativa de fatos, eventos ou disposição de objetos do passado e, nesse sentido, apresentar a mesma como "máquina de guerra" que possibilite a ativação popular do patrimônioterritorial.

Cabe a ressalva de que não se arvora neste artigo fazer um tratado metodológico sobre a pesquisa na Geografia Histórica. Outros textos citados alhures já foram escritos defendendo essa ampla temática. Pretende-se todavia que a observação e o cuidado no trato desse elenco de pressupostos protejam o pesquisador de riscos recorrentes e remeta a uma pesquisa que vá para além da classificação de objetos fixos num determinado espaço-tempo.

\section{Do patrimônio como elemento puntiforme ao espaço como totalidade}

O primeiro dos riscos numa abordagem de Geografia Histórica vinculada ao patrimônio é o sustentar-se naquela para "naturalizar" o que é tido ou tomado como patrimônio. Não obstante o entendimento sobre os critérios para a seleção do que deve ser tombado pelos órgãos responsáveis em variadas escalas, deve-se ter a clareza de que o "eleito" responde a determinados critérios, mas se distancia de uma totalidade que é absolutamente mais complexa e diversa do que é enumerado, limitado espacialmente ou classificado pelo poder formal. Como bem alerta Costa (2017, por exemplo), intervenções urbanas sob o signo da patrimonialização e, sua cara metade, turistificação tendem a fragmentar o espaço, segmentando-o, como é próprio do capitalismo, perde-se assim a perspectiva de um espaço mais amplo, complexo e, normalmente, excluído e alienado em relação aos investimentos e visibilização dados a uma determinada área tombada.

Destaca-se aqui que não se é contra a defesa de sítios ou práticas que, por determinados critérios, devam ser protegidos, o que se alerta é sobre as mudanças de usos, que alterem a própria essência existencial do que foi tombado ou que se iluminem determinados pontos do espaço em detrimento a um mais amplo espaço da vida das pessoas que habitam aquela localidade. Dois exemplos cabais podem ser relacionados: no primeiro caso, a experiência de gentrificação do centro histórico de Salvador iniciado na década 1990 (Andrade \& Brandão, 2009) quando houve a expulsão da população local e a criação de um espaço mítico, turístico e maquiado que alterou bruscamente os usos e funções urbanas que aquela região exercia no contexto da cidade. Equipamentos foram instalados e as demandas comerciais se impuseram às resistências residenciais do entorno, criando um espaço sem vida, ou melhor, com vida e serviços orientados para o usufruto dos turistas ou dos soteropolitanos que pudessem pagar para "consumir" o novo Pelourinho. Um simulacro com luzes de um espaço passado, sob a chancela da patrimonialização, que se impôs autoritariamente no centro da complexa realidade urbana da capital baiana.

Um outro exemplo que salta aos olhos é a realidade das pequenas cidades mineiras tombadas pela UNESCO, com destaque a Ouro Preto e Diamantina. Fruto de uma extensa pesquisa documental e empírica, Costa (2010) mostra como a população mais fragilizada, que ocupa as periferias dessas duas cidades, permanece alheia à própria história do espaço e, principalmente, "esquecidas" nas políticas públicas que canalizam recursos à porção tombada do espaço urbano.

$\mathrm{O}$ processo histórico do acontecer social se dá como um conjunto de possibilidades que se enredam e se transformam em bases simbólicas e concretas num contínuo embate entre o universal e particular, este e aquele mais ou menos distante a partir de cada realidade espacial (universal como tendência e particular como acontecer real dos lugares). Assim, os eventos se realizam seletivamente numa mesma totalidade. Selecionar determinados desdobramentos de eventos acontecidos no desenrolar da vida cotidiana que produz o espaço banal "implica uma grande armadilha de não levar em consideração um axioma a ele ligado: a sua pluralidade. A seleção de um desdobramento espacial em detrimento a outros tende a deixar pessoas, hábitos e lugares excluídos das políticas de patrimonialização.

A Geografia Histórica, ao passo que estabelece análises sobre dinâmicas territoriais pretéritas, possibilita a visibilização de grupos sociais oprimidos/omitidos historicamente na produção do espaço social. Assim, os "novos" escritos postos à baila por essa área da Geografia se 
constituem como instrumentos para visibilizar eventos e atores e constituir um campo de resistência e permanência de espaços, saberes e práticas sociais.

\section{Qual a "verdade" presente nas fontes primárias?}

Deve-se também estar alerta às análises que consideram documentos e textos históricos como verdades consolidadas. Certamente eles expressam "uma" verdade, no entanto, também derivam de seleções, intencionalidades e, principalmente, interpretações. Por vezes, na ânsia de localizar algum registro documental ou texto histórico que sustente uma hipótese, incorre-se no erro de não tomá-lo como uma possibilidade diante de uma miríade de outras omitidas. Não se trata de descartar as fontes primárias ou secundárias, mas de relativizar o seu uso e, quando possível, confrontar com outras fontes.

No caso do Brasil, boa parte dos documentos formais produzidos no período colonial era feita por fidalgos (portugueses ou descendentes) e, evidentemente, respondiam ao interesses desse grupo frente aos diversos outros agentes que ocupavam e produziam o vasto espaço brasileiro.

Dentre os incontáveis exemplos de dinâmicas territoriais pretéritas que poderiam clarificar essa ponderação, selecionou-se aqui o caso da criação de uma vila no distante sertão de Rodellas, a oeste do Rio São Francisco. Andrade e Andrade (2019, p.55) indicam que

em 23 de agosto de 1753 que, respeitando a provisão régia de cinco de dezembro de 1752, foi erigida a vila de São Francisco das Chagas da Barra do Rio Grande, hoje simplesmente a cidade de Barra na mesorregião V ale Sanfranciscano da Babia. A localização estratégica foi fator fundamental na elevação desta vila; ela foi fundada num "entroncamento" de vias fluviais que articulava o norte e o sul através do rio São Francisco e acessava por caminhos hidricos on terrestres as terras/minas do leste e oeste. A vila é decorrente de um arraial formado por indios pacificados a partir de orientação do então Governador Geral D. João de Lancastro ao final do século XVII. Esta medida foi tomada para evitar as invasões e ataques do gentio (Acoroazes e Mocoazes) às fazendas de gado da região. Os óbices demográficos e materiais daquelas distantes terras, porém, levou ao retardo da elevação do povoado a vila, só ocorrendo depois de mais de meio século.
O discurso presente sobre a necessidade de "pacificar" os indígenas apresenta esse grupo de moradores originais daquele espaço como um óbice a ser vencido para a implantação das fazendas de gado e livre circulação dos fluxos comerciais de tempo lento que por ali passavam conectando o norte da colônia e o porto de Salvador às interiores regiões mineiras.

Os indígenas "hostis" à empresa colonizadora foram dizimados ou incorporados como trabalhadores braçais das fazendas de gado. Hoje, contraditoriamente, elementos marcantes da cultura local derivam desse encaldeamento entre opressor/colonizador e oprimido/indígenas. As festas de gado e vaquejadas locais guardam cores desse perverso passado, entretanto, são apresentadas como mera alegoria, sem a profundidade que possibilite visibilizar o papel histórico dos índios Acoroazes e Mocoazes como ocupantes primeiros daquele território.

O saber formal, presente nas fontes primárias documentais, reverbera a dominância de um grupo sobre os outros e a Geografia Histórica é um campo disciplinar que pode apresentar uma série de novas leituras, interpretações e informações que sugiram outras possibilidades de ver e entender grupos e dinâmicas territoriais do passado.

\section{O risco da anacronia}

Uma outra "armadilha" contumaz nos estudos da Geografia Histórica diz respeito à anacronia no uso de conceitos e terminologias. $\mathrm{O}$ uso de constructos hodiernos para explicar dinâmicas de tempos mais recuados deve ser feito com rigoroso aporte conceitual sob pena de produzir análises sem sustentação nas diferentes temporalidades e processos territoriais que se davam a partir de outras bases.

É exemplar a discussão desenvolvida por Andrade (2013) para a aplicação do conceito de rede urbana à dinâmica territorial do Brasil Colonial. Não obstante o amadurecimento conceitual de urbanização e, por derivação, da rede urbana estarem vinculados ao processo de industrialização vivido no continente europeu pós século XVIII, parece-nos adequado aplicar tais conceitos a outros tempos e espaços, entretanto com as necessárias ressalvas para que $\mathrm{O}$ entendimento não se dê de forma anacrônica.

No uso supramencionado dos ditos conceitos para entender a dinâmica territorial do Recôncavo baiano e as suas articulações internas (Andrade, 2013), fez-se necessário primeiramente 
definir o que era o urbano para aquele tempo e espaço, com o claro entendimento de que aqueles ajuntamentos humanos de então diferenciavam-se sobremaneira do que se define como urbano na nossa contemporaneidade (medidas as variações de critérios entre os países). Tomou-se, então, como o urbano para o Brasil setecentista as sedes das vilas e cidades nos extensos termos municipais então definidos pelo poder formal. Essas unidades parcamente povoadas exerciam uma centralidade demográfica, econômica e jurídica sobre um longo e soberano espaço "rural".

A partir desses núcleos de povoamento, conforme se comprova em diversas fontes primárias, estabeleciam-se trocas interiores que, por vezes, subvertiam as ordens verticalmente impostas pelo poder central de Lisboa/Portugal e alinhavavam uma rede regional que rompia com o modelo tipicamente arboral ou em forma de "bacia de drenagem" (Moraes, 2002, p.85).

Uma rede tipicamente urbana que articulava pontos a partir de fluxos de mercadorias e pessoas num tempo lento, medidas as dificuldades de circulação pelo território que confirma a possibilidade de uso de tal conceito, ainda que em tempos mais recuados, desde que sejam feitas as argumentações teóricas que justifiquem a aplicação para o entendimento da dinâmica territorial pretérita.

Outros autores também tratam de redes urbanas estruturadas em tempos mais recuados a exemplo de Costa e Moncada (no prelo) na avaliação que fazem sobre o complexo e intricado espaço pré-colombiano no México (produção sistema intensivo, concentração demográfica numerosa, registros e calendários, artes, edifícios e cidades monumentais, diferenciação entre rural e urbano, articulação em rede e rotas comerciais, estrutura e diferenciação político-econômica e religiosa, centralidade e "hinterlândia") com os cuidados teóricos e metodológicos para justificar o uso de conceitos amadurecidos em tempos mais recentes que o fenômeno estudado.

\section{Os "hiatos temporais"}

É impossível apreender a totalidade do espaço social dada a sua dinâmica e a incontável possibilidade de arranjos. Considerando esse axioma para a nossa contemporaneidade, a tarefa de buscar dinâmicas territoriais em tempos pretéritos é ainda mais árdua, pois se dá a partir de um limitado conjunto de fontes, especialmente nos espaços e tempos em que há lacunas de documentação.
Alguns espaços luminosos (Santos \& Silveira, 2001) no passado, como as capitais coloniais, Salvador e Rio de Janeiro, ou áreas de grande interesse econômico, vilas mineiras, por exemplo, guardam grande volume de documentação em condições de serem transformadas em texto histórico; todavia, há outros espaços que viviam dinâmicas territoriais em pontos opacos aos interesses imediatos da empresa colonial e, nesse sentido, possuem pequena disponibilidade de documentação primária (textos escritos, cartografia e iconografia). Tem-se assim, em oposição aos "períodos densos", os "hiatos temporais" à pesquisa na Geografia Histórica o que dificulta a apreensão das dinâmicas espaciais pretéritas (Vasconcelos, 1999).

Dois importantes alertas merecem menção para esses casos em que aparecem os ditos "hiatos temporais": o primeiro é o risco de elaborar especulações e produzir textos sobre territórios do passado com pouca sustentação documental e incorrer no equívoco de embasá-los em constructos do presente ("verdades consolidadas" em textos secundários ou na própria formação do pesquisador). $\mathrm{O}$ segundo alerta diz respeito ao entendimento que a ausência de informação documental não significa o "vazio" de ocupação, mas uma outra lógica que predominava no espaço "não" documentado, assim, a "não informação" também é um dado significativo a ser considerado na pesquisa em Geografia Histórica. Ratifica-se, então, que o texto resultante de uma análise revela apenas uma possibilidade interpretativa diante do conjunto da complexa e dinâmica totalidade socioespacial.

Alternativas viáveis ao se deparar com esse óbice na pesquisa na Geografia Histórica são: Procurar informações nas entrelinhas de textos que tangenciem o objeto em foco na pesquisa. Outra boa estratégia é ler/buscar as pistas que a falta de documentação sobre um determinado espaço-tempo apresentam, como a obliteração de agentes de produção do espaço, omissão intencional de dados pelo poder central ou mesmo a pouca importância dada a determinadas regiões coloniais.

Abreu (2005) já havia sinalizado acerca desse problema e indicado como alternativa, no tocante ao trato com a cartografia histórica, a possibilidade de produzir mapas conjunturais a partir da coleta de informações de outras fontes de pesquisa. Assim o fez para a realidade urbana do Rio de Janeiro e tal metodologia já foi apropriada por outros estudos como o de Andrade (2013) sobre o Recôncavo baiano. 


\section{Interesses diferenciais na produção do espaço: o papel dos agentes}

Uma alternativa para o risco de naturalizar os eventos (tomar "fatos" históricos como verdades incontestes) é buscar identificar agentes de produção do espaço e suas intencionalidades, entretanto é fundamental estar atento à variação desses para cada dinâmica espaço-temporal. A identificação dos agentes nomeia e personaliza os eventos, sejam eles conjunturais ou estruturais.

Num claro esforço teórico e metodológico, vários autores já tentaram estabelecer classificações dos agentes de produção do espaço, com destaque para Corrêa (1995), que abordou o caso específico da cidade capitalista da nossa contemporaneidade e de em Vasconcelos (1997) que, recuando no tempo, apresentou os agentes de produção do espaço para as cidades no Brasil Colonial. Com um olhar mais focal, Andrade (2013) aprofundou a relação quando analisou o caso empírico do Recôncavo baiano setecentista. O que ratifica que a variação no tempo e espaço muda, determinantemente, o elenco e os papéis dos agentes.

É revelador notar que um mesmo agente, num mesmo tempo cronológico da história, assume papéis diferentes diante da articulação de forças desiguais (enfrentamento ou articulação/aproximação com outros agentes) que atuam na dinâmica territorial de produção e uso dos territórios, a exemplo do papel diferencial da Igreja na produção do espaço no Recôncavo baiano e nas Minas Gerais no decorrer do século XVIII. Pode-se ampliar esse olhar na comparação com outros espaços da América Latina, a exemplo do que fazem Costa e Moncada (no prelo) quando mapeiam os presídios e conventos, objetos concretos da colonização, na estruturação de uma verdadeira rede de localidades estrategicamente dispostas na ocupação e exploração do atual território mexicano.

Destaca-se que a ação dos agentes hegemonizados ganham pequena visibilidade tanto na documentação formal como na materialidade do território, entretanto eles existem e, portanto, são passíveis de serem cartografados e analisados nos seus papéis de outrora e atuais, dando assim margem a pensarmos em outras dinâmicas territoriais e possibilidades patrimoniais a serem clarificadas pelas análises e textos da Geografia Histórica. Essa possibilidade aqui sugerida confirma o vínculo entre a produção de saberes dos estudos da Geografia Histórica que "iluminam" dinâmicas territoriais do passado e o seu uso, na atualidade, por grupos populares, para que esses ativem o patrimônio-territorial vinculado às suas práticas, por vezes, omitidas ou oprimidas ao longo da história desigual e perversa do processo capitalista de colonização, mormente no contexto da América Latina.

\section{O texto histórico como uma das possibilidades analíticas para um dado arranjo espaço-temporal}

A produção de um estudo de Geografia Histórica não prescinde de um claro entendimento sobre a categoria analítica do tempo e suas derivações como as temporalidades técnicas e as estratégias de periodização (Andrade, 2013).

Seguindo essa perspectiva, três possibilidades analíticas se apresentam inicialmente: Num "diálogo" direto com a proposta braudeliana (Braudel, 1978), o primeiro viés de abordagem do tempo diz respeito ao entendimento dos possíveis encontros concretos entre tempo e espaço na realização dos eventos. Como escreveu Santos (1997, p.114), "O evento é a flecha do tempo num dado espaço". Em cada canto do mundo, a infinita possibilidade de realização de acontecimentos é sempre mediada pela temporalidade técnica e condicionante espacial daquele ponto específico do planeta onde se encontram os agentes que vivem o evento. A maioria dos eventos tem apenas repercussão local, outros, entretanto, podem ter repercussões globais. Visto desta forma, decisões verticais, em redes hierárquicas, têm rebatimento no nível das horizontalidades, do viver cotidiano. Assim, fatores exógenos, atendendo a critérios supra-locais, podem criar fatos novos para o local de vivência das pessoas que passarão a contar com esta nova realidade cotidiana.

Uma segunda possibilidade analítica é que, num mesmo tempo cronologicamente datado, podem coexistir, no mundo, diferentes temporalidades técnicas. Como exemplo, pode-se citar o caso do Brasil do século XXI onde convivem espaços onde ainda se dão usos tradicionais e arcaicos da terra, regulados pelos domínios da natureza com técnicas primitivas de cultivo e sujeitos às determinâncias de uma natureza que pode ser hostil (secas mais prolongadas, pragas, etc.) aos seus mais básicos interesses, e outros, não tão distantes (sertão nordestino e MATOPIBA "), onde o desenvolvimento da química fina e biogenética possibilitam o encurtamento do tempo das safras ou o crescimento contínuo e estimulado de espécies animais como os galináceos, além do 
controle de pragas e maior produtividade a partir da produção transgênica. É o domínio técnico de uma e outra situação que determina a relação com o tempo da safra, do crescimento dos animais e, mesmo, com as demais relações sociais que se desenrolam a partir da produção.

Terceiro, o tempo é acelerado pelas técnicas e essas tocam o espaço geográfico seletivamente, assim, considerando que cada espaço possui uma dada temporalidade técnica e uma dada conjunção de agentes que o produzem, não se pode periodizar o tempo cronológico de forma homogênea, sob o risco de severa anacronia. O tempo e suas rupturas são diferentes para cada fragmento do mundo. Como exemplo, podemos pensar em quão incoerente deve ser a cronologia eurocêntrica que divide o tempo em Idade Antiga, Medieval, Moderna e Contemporânea, para os Judeus, para o mundo árabe, para os antigos povos pré-colombianos e mesmo para o extremo oriente que adotam um outro padrão de periodização a partir da lógica local.

\section{A cartografia como instrumento de pesquisa da Geografia Histórica}

A ação social se espacializa, essa é a premissa norteadora da Geografia, assaz esse axioma, esta ciência tem ontologicamente o espaço geográfico como categoria analítica nodal dos seus estudos. Nesse sentido, e abrindo mão de um desdobramento epistemológico sobre essa variável teórica, tem-se na cartografia um instrumento de apoio absolutamente necessário aos estudos geográficos, visto que ela possibilita um manifesto desdobramento dos eventos sociais, selecionados, no território. Fator fundamental para os estudos pretensamente geográficos.

Mormente para a pesquisa no campo da Geografia Histórica, recorrer às representações cartográficas na amplidão de possibilidades que ela oferece (mapas de época, iconografia, mapas conjecturais, cartografia indutiva, cartogramas) significa complementar fontes e abrir outras possibilidades de "ler" a dinâmica espacial vivida em tempos recuados.

Uma ressalva de base quando se faz uso desse recurso é que todo mapa representa uma perspectiva redutiva ao caráter complexo e multidimensional do espaço geográfico. Assim, mesmo considerando que os eventos se territorializam e a cartografia possibilita a visibilização/leitura da espacialidade das dinâmicas territoriais, não se pode perder de vista que, conforme informado alhures nesse mesmo artigo, os mapas são desdobramentos de intencionalidades de quem se propõe a fazer o desenho.

Em relação à base de dados cartográfica, tem-se como fundamento que mapas em diferentes escalas abrem diferentes possibilidades de análise, pois se vê coisas diferentes.

Desta forma, e considerando que a ação dos agentes de produção do espaço pode ser mapeada, abre-se a possibilidade analítica de "enxergar" em mapas de diferentes escalas a resistência que também se territorializa. Ou seja, a cartografia que historicamente é utilizada como instrumento de poder (conhecer, tomar posse, batizar, oprimir) como teoriza e empiriciza Araújo (2001) para o caso da formação da atual fronteira oeste do Brasil, também pode dar pistas e ensejar análises emancipatórias.

\section{As intencionalidades e "limitações" técnicas por trás dos mapas}

Ainda vinculado ao pressuposto anterior, há que se ter clareza que quem fez o mapa ou o documento traz consigo um posicionamento ideológico. Nesse sentido, o pesquisador deve buscar as intencionalidades e também os limites técnicos (caso de precisão escalar e localização) na construção dessas importantes fontes de pesquisa, sempre alerta ao fato de que a dinâmica territorial é muito mais complexa que as possibilidades de revelá-la em um mapa.

Os dois exemplos que seguem clarificam como que a feitura de um mapa, notadamente os mapas históricos, explicitam informações desejadas e omitem outras dinâmicas territoriais que se apresentam ao pesquisador apenas nas entrelinhas.

O primeiro exemplo é a Figura 1, um mapa da comarca da Baía de Todos os Santos no início do século XIX, mas com registros coletados no século anterior, fato habitual para um tempo de escassas informações sobre os espaços ocupados e em que a cartografia produzida era uma "soma" de dados de mapas anteriores. Considerando ainda uma relativa inércia espacial, pode-se afirmar que os equipamentos dispostos na imagem (estradas e núcleos de povoamento, principalmente) possuem uma existência mais recuada, possivelmente, no século XVIII.

Neste mapa aparecem destacados os "caminhos reais", assim chamados por serem as vias principais dos fluxos formais que circulavam no tempo lento da rede que ligava os principais pontos a serem explorados do território colonial aos portos atlânticos (cabeça de ponte). 
Verifica-se a presença dominante da cidade de Salvador (não mais capital colonial, desde 1763, mas ainda como um dos principais portos do Brasil) na península que "fecha" a Baía de Todos os Santos, e para onde vetorizavam os caminhos terrestres e hídricos num evidente desenho de bacia de drenagem ou arboral típico do período colonial.

Percebe-se também, numa leitura imediata, a presença de uma densidade de informações sobre povoamentos no entorno da baía, no chamado Recôncavo baiano, uma área povoada e ocupada economicamente por lavouras de cana-de-açúcar, tabaco e mandioca, prioritariamente.

O que, todavia, não está posto é que havia uma série de articulações internas à região, conforme comprova Andrade (2013) com base em análises de fontes documentais e cartográficas, que revelam uma rede regional bem integrada para aquele tempo e espaço com a proeminência de Salvador e a centralidade interior de cinco vilas (São Francisco do Conde, Santo Amaro, Cachoeira, Maragogipe e Jaguaripe), todas criadas até o primeiro quarto do século XVIII. Os fluxos que movimentavam essa rede caracterizavam uma subversão do território colonial às ordens da Coroa, pois possibilitavam o abastecimento interno, via trocas por mascates ou feiras livres, em detrimento ao controle e abastecimento da alfândega de Salvador. Essa e outras dinâmicas territoriais fogem da intencionalidade da produção do mapa, entretanto são possíveis de serem verificadas para além do espaço formal cartografado. Além desses, variando a escala de análise para o foco local, há a possibilidade de identificar agentes de produção do espaço pouco registrados nos documentos formais, como o caso dos roceiros, negros alforriados, quilombolas e escravos urbanos. $O$ segundo exemplo aqui trabalhado (Figura 2), diz respeito a um registro da região da baía de Todos os Santos ao atual litoral sul do estado da Bahia. Esse documento cartográfico foi publicado em 1754 e chama a atenção, para a análise aqui feita, pelo texto que traz no seu canto alto esquerdo: "Etendue de Pais desert et peu connu". Ou seja, em meados do século XVIII, toda a extensão da margem esquerda do rio São Francisco é apresentada formalmente como um espaço deserto e pouco conhecido.

Isso nos leva a questionar a posição de quem faz o mapa e a intencionalidade para qual ele serve, visto que os sertões da Bahia já figuravam como rotas de estradas terrestres que seguiam para as minas e as ligavam à pecuária extensiva das províncias do norte e, principalmente, ao porto de Salvador.

Figura 1 - Planta do porto e comarca da Bahia de Todos os Santos.

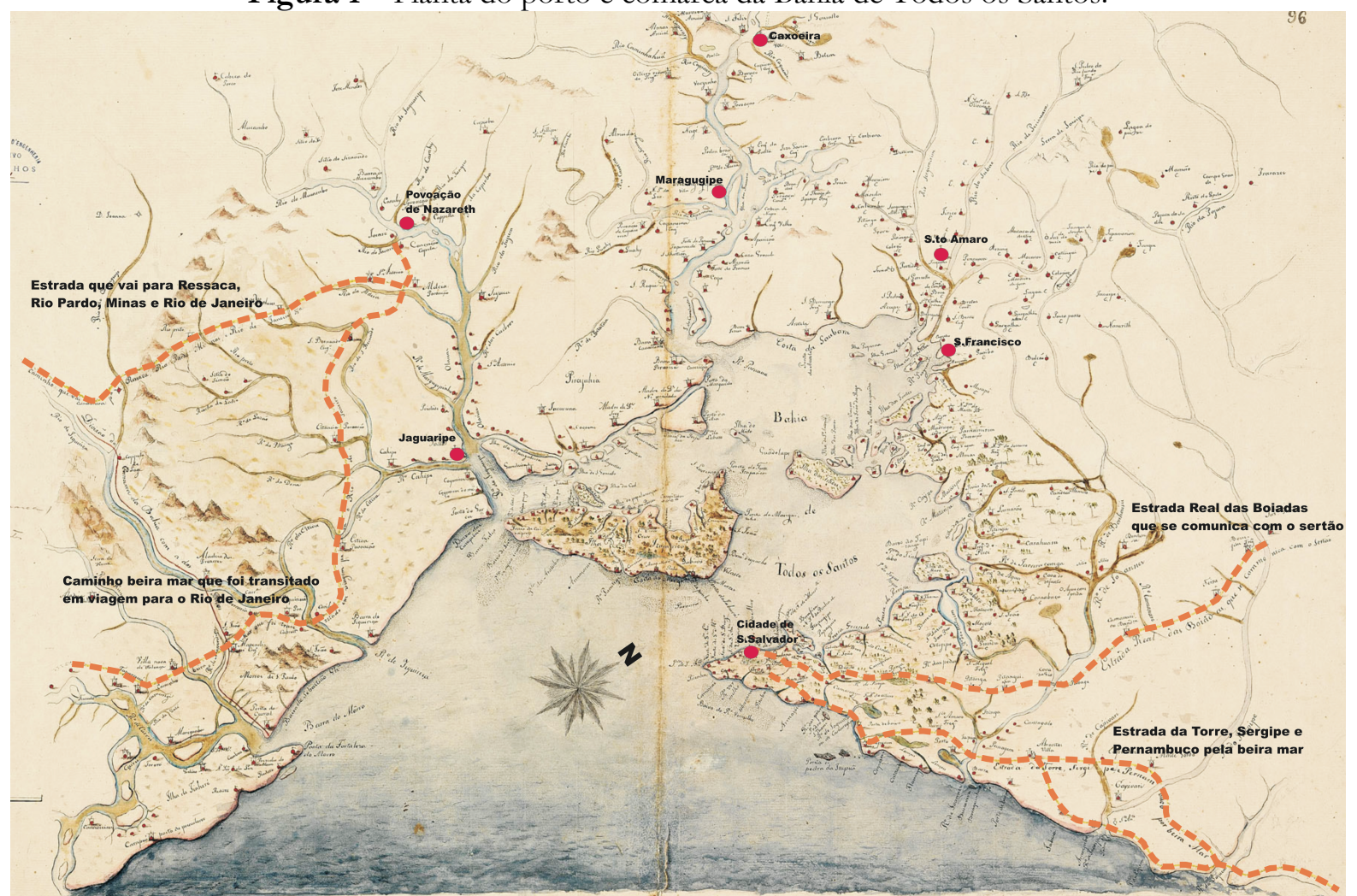

Fonte: Exército Português.Reg. nº 8762, Post 1808. grifo nosso.

PatryTer | ISSN: 2595-0169 | vol. 4 | n. 7 | março 2021 | pp. 63-77 | Artigo 
Conforme sinalizam Andrade e Andrade (2019), é significativo observar que a vila de Nossa Senhora da Barra do São Francisco tinha sido fundada um ano antes da publicação do mapa e que no início dos setecentos já havia uma determinação do Capitão Geral da baía para que a região fosse pacificada por "fazendeiros", omitindo, em todos esses documentos, a presença dos índios Acoroazes e Mocoazes que habitavam originalmente naquelas terras do Além São Francisco e que são apenas mencionados como um "óbice" a ser vencido na ocupação do território pelo agente colonizador (assunto mencionado no item três deste artigo).

Figura 2 - Suíte du Bresil: depuis la baye de tous lês Saints jusqu'a St. Paul.

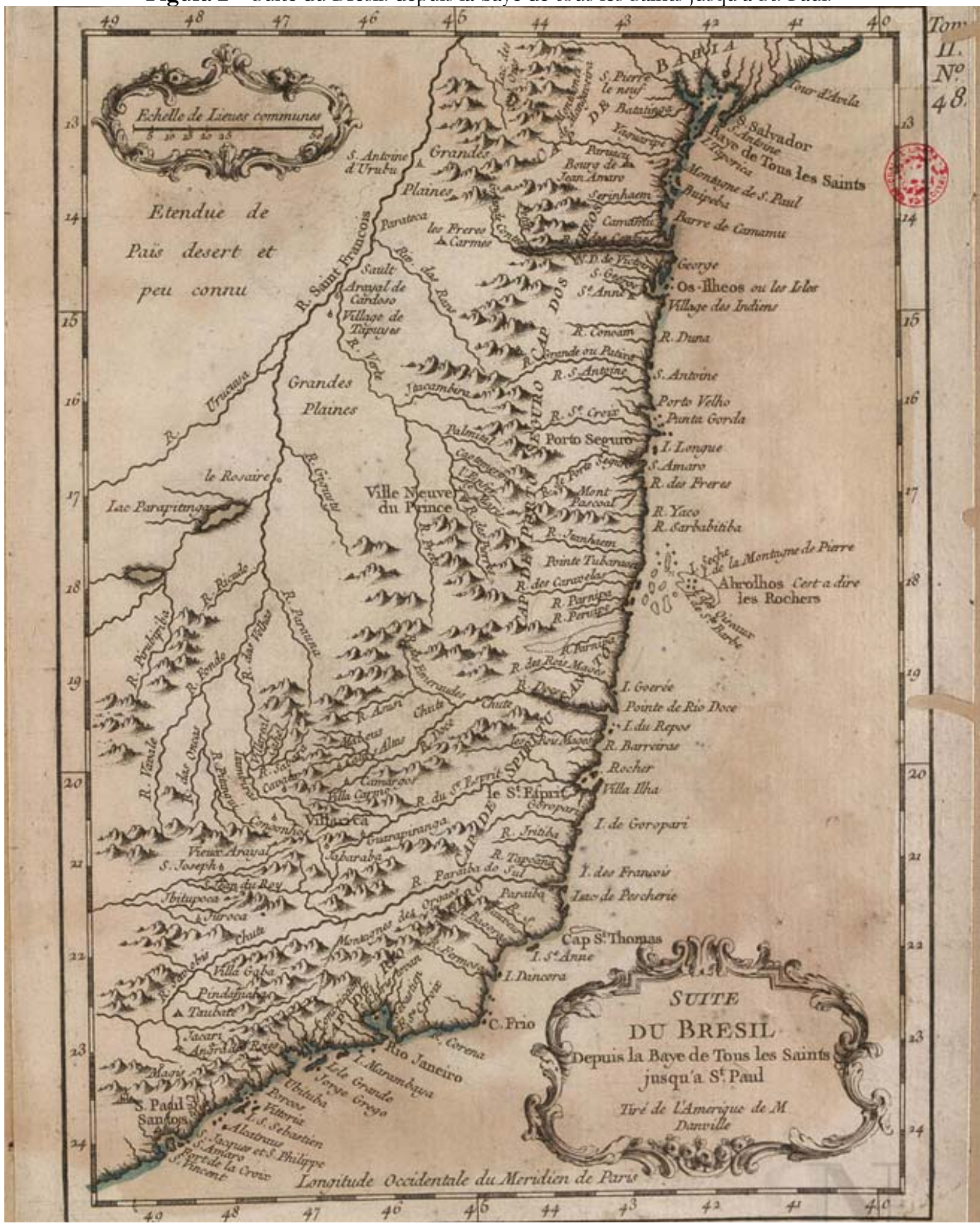

Fonte: Biblioteca Nacional. (1754). Jacques Nicolas Bellin, ARC.010,12,039.

PatryTer | ISSN: 2595-0169 | vol. 4 | n. 7 | março 2021 | pp. 63-77 | Artigo 
Nesse mesmo sentido, merece menção como que a intenção de quem faz o mapa revela verdades sobre o território que se propagam no tempo em que é publicado e nos tempos que seguem visto que se apresenta como uma leitura fidedigna do espaço. Caso emblemático é tratado numa série de estudos apresentados por Hirt e Lerch (2014) sobre a atual Bolívia. As autoras mostram como que foi forjada, ao longo da história colonial, uma forma hegemônica de pensar o território a partir da cartografia oficial alijando de visibilidade os mais numerosos habitantes locais, os indígenas. Propõe-se no referido estudo a produção de uma contracartografia com a mudança da perspectiva do olhar, ou seja, um conjunto de novos mapas, partindo de registros históricos, porém a partir do protagonismo indígena.

Ratifica-se aqui o papel da Geografia como ciência do presente e, desta forma, apresenta-se concretamente uma contribuição da Geografia Histórica e da Cartografia na "iluminação" de fissuras, resistências, transformações e permanências que possibilitem outras leituras das dinâmicas territoriais passadas, recontando a história do território sob outras bases e ajudando a compreender os arranjos do presente.

\section{Diversidade de fontes como fator de enriquecimento das análises}

A ausência de uma fonte não deve impedir a pesquisa sobre uma dada dinâmica territorial. $\mathrm{O}$ pesquisador de Geografia Histórica deve valorizar e utilizar as diferentes fontes com as suas respectivas linguagens e especificidades: oral, literatura, jornais, documentos oficiais, cartografia, iconografia.

Focar em uma única base de dados ou fonte pode ser uma alternativa de trabalho para a pesquisa em lugares ou tempos com um maior volume de informações (fontes primárias) disponíveis. Há, entretanto, que lidar com duas variáveis bastante comuns na pesquisa da Geografia Histórica: primeiro os chamados hiatos temporais (já mencionados no item quatro deste artigo), períodos ou recortes espaciais com escassez de fontes; segundo, quando a variação da fonte de pesquisa possibilita "ver" outros agentes ou dinâmicas territoriais, a exemplo da combinação, quando possível, entre bases documentais e literatura ou registros orais, como fazem Pinheiro e Silva (2004).

É evidente que o uso de diversas fontes perpassa pelo rigor científico no trato dessas bases como material substantivo para sustentar o argumento de um texto na academia. A própria abordagem metodológica das mesmas implica uma adequação ao método adotado no desenvolver da pesquisa.

Ratifica-se, todavia, que a diversificação das fontes possibilita confrontar "realidades" a exemplo do que faz Maluly (2019) quando apresenta uma série de cartogramas desenhados a partir do relato de um viajante, neste caso de Auguste de Saint-Hilaire, nos anos de 1816 e 1817, e confronta esses mapas com outros feitos na época, para revelar o que chama de "espaços de exceção". Vazios de informação na cartografia da época, mas que, na verdade, eram áreas ocupadas por indígenas indesejáveis à empresa colonial que explorava as Minas Gerais.

"Ver" nas entrelinhas, buscar outras leituras além das explícitas e identificar o que não está posto, o não dito, como informação (a exemplo da análise feita sobre as Figuras 1 e 2) gera a possibilidade de encontrar pistas que ensejem a produção de outros mapas de uma cartografia contra-hegemônica.

É a estratégia subversiva, anteriormente sinalizada, de diversificar fontes para encontrar na micro-história a revelação de dinâmicas territoriais complexas e dar visibilidade a outros agentes na produção do espaço de outrora. Muitas vezes essa revelação pode acontecer no confronto entre a memória de um relato individual e a memória coletiva de uma determinada expressão social, como sugere Alvarado-Sizzo (2019)

\section{A Geografia Histórica como "máqui-na de guerra" para a iluminação de patrimônios-territoriais}

Ao longo da segunda metade do século $\mathrm{XX}$, produziu-se no Brasil uma série de estudos pretensamente associados à Geografia Histórica que seguiam uma metodologia rígida e que apresentavam cidades e regiões urbanas a partir da descrição de componentes fisiográficos, localizacionais, e da disposição de equipamentos de infraestrutura econômica, todavia careciam de análises críticas e apresentação dos processos que movimentavam a dinâmica territorial, tanto para o passado como para o presente (Abreu, 1994).

Para além desse modelo descritivo das monografias urbanas que efetivamente tiveram um papel importante na construção da Geografia brasileira, é necessário pensar no novo papel assumido pela Geografia Histórica a partir da construção de análises sobre dinâmicas territoriais pretéritas que permitam atualizar o olhar sobre a 
nossa contemporaneidade a partir de outras bases e discursos históricos.

Assume-se assim a premência de que os estudos da Geografia Histórica sejam verdadeiras "máquinas de guerra" que iluminem grupos e práticas ancestrais e apresentem novas lógicas constitutivas dos territórios de hoje.

Essa perspectiva se aproxima do que se propõe neste artigo: tem-se nos estudos da Geografia Histórica a possibilidade concreta de iluminar, construir e cartografar patrimôniosterritoriais pouco visibilizados pela historiografia até então.

Considera-se o patrimônio-territorial, conforme Costa (2017), como uma resistência que se territorializa. Resistência no sentido de que são expressões de um povo sobre um território, algumas inclusive perdidas ou profundamente modificadas ao longo da história (a exemplo do legado imaterial dos povos que sofreram etnocídio no processo de colonização latino-americano). Costa (2016, p.2) é enfático ao afirmar que "o utopismo patrimônio-territorial latino-americano (...) dá vOz aos indígenas, às mulheres, aos pobres urbanos; legitima a diversidade das memórias nacionais e acusa desmantelamentos por guerras e ditaduras. Reconhece que a mudança social no continente está nas mãos dos despojados e dos humilhados, perfazendo-se neles próprios". Entende-se, assim, que a produção da Geografia Histórica, reveladora de dinâmicas territoriais do passado, deve ser utilizada, no presente, como instrumento fundamental para a ativação popular desse patrimônio-territorial, símbolo da resistência de povos oprimidos e que tem, no resgate da história que os visibilize, a possibilidade de subverter a história posta e vivificar novas territorialidades sustentadas em práticas ancestrais omitidas.

Os riscos para estabelecer esse vínculo são muitos, como também o são para aprofundar estudos sobre dinâmicas territoriais do passado. Nesse sentido, o rigor metodológico pavimenta um caminho seguro a trilhar nessa imensa miríade de possibilidades de estudos na Geografia Histórica, muitos tidos como tal, mas restritos a relatos descritivos ou carentes de base espacial, como sinaliza em estudo crítico Costa (2015). Sugere-se aqui como uma alternativa metodológica a proposta feita e aplicada por Vasconcelos (2002), na qual o autor propõe quatro fases essenciais para os estudos neste campo: o estabelecimento criterioso de uma periodização adequada àquele tempo e espaço, a contextualização em diferentes níveis escalares, a identificação dos agentes de produção do espaço e os interesses em jogo e, por fim, como elemento essencial, o mapeamento e análises acerca das transformações espaciais atinentes a cada período estudado.

Sob essa base metodológica, não se deve descartar a importância que há na análise das paisagens reconstituídas a partir da distribuição de "alguns" elementos naturais ou técnicos numa dada disposição espaço-temporal. A análise da paisagem permite que a Geografia Histórica revele "outras" bases patrimoniais e se constitua em instrumento de resistência.

Considera-se que, a partir desses pressupostos à pesquisa, é possível, então, ativar o patrimônio-territorial a partir da periferia ou dos grupos que foram submetidos às forças hegemônicas. Entender o "novo" que surge do encaldeamento entre a imposição de determinados grupos que atuam estrategicamente sobre o território e a vida banal - dimensão existencial (sincretismo, resistência, novas identidades criadas - exemplo das vaquejadas, do cristianismo vernacular).

Os excluídos não podem ser vistos (ou não vistos/omitidos da história territorial) como variáveis sem emoção. Devem ser entendidos como parte incluída de um sistêmico e perverso processo socioeconômico que se dá em bases territoriais e, portanto, com diferentes e sucessivas temporalidades. Buscar essa espacialidade da dominação presente, via de regra, na documentação histórica, é usar a ciência como "máquina de guerra" para ativar o patrimônio territorial. Para além das formas, é possível vislumbrar outras histórias a partir da análise de dinâmicas territoriais de tempos passados.

A construção de análises que apresentem a dimensão existencial do espaço permite, por exemplo, explicar as dinâmicas territoriais a partir de elementos e olhares endógenos e não a partir de constructos exógenos. Caso exemplar da América Latina que é sempre "explicada" a partir de um olhar eurocêntrico ou anglo-saxão e pouco se viu por dentro. Esse alerta feito por Santos (2006) e Lemos (2018) reverbera em trabalhos que se avolumam nas últimas décadas, a exemplo dos escritos publicados regularmente em revistas científicas como a PatryTer - Revista Latinoamericana e Caribenha de Geografia e Humanidades, que se estrutura segundo essa perspectiva aqui indicada.

Fundamentalmente, entende-se, por exemplo, que os modelos analíticos impostos de fora podem explicar a realidade latino-americana a partir da lógica econômica e da industrialização e, com esse enfoque, corrompido, economicista, os pobres são entendidos como uma variável, sem 
emoção. Não como parte de um sistêmico e excludente processo socioeconômico capitalista. Deve-se, então, estar alerta para o fato de que os resultados obtidos numa pesquisa são resultantes de "uma" realidade vivida, uma dinâmica social espacializada em relações territoriais entre oprimidos e opressores. E que ambos devem ser mapeados sob o risco de olhares míopes e estereotipados sobre o território usado no passado e agora.

\section{Considerações finais}

Entendendo as limitações óbvias de um aprofundamento de discussão e análise no campo de um único artigo científico, ratifica-se que o que se pretende com esse escrito é acrescentar elementos ao diálogo teórico-metodológico na construção da Geografia Histórica brasileira.

Assim, num exercício de síntese, apresentam-se a seguir as ideias fortes aqui defendidas como pressupostos conceituais ou metodológicos para quem se propõe a fazer estudos no campo da Geografia Histórica vinculando-os ao processo em curso de ativação popular do patrimônio-territorial.

(1) A ação social dos agentes de produção do espaço (hegemônicos e hegemonizados) deixa marcas concretas no território usado, desta forma é passível de representação cartográfica e registro textual que deve ser buscado/produzido a fim de dar visibilidade a todos os agentes, o que possibilita mais de uma leitura do evento vivido.

(2) Os estudos de Geografia Histórica possibilitam abrir luz a novas interpretações sobre os processos que estruturaram dinâmicas territoriais no passado. Uma boa alternativa para alcançar essa possibilidade é a diversificação e cruzamento de fontes de pesquisa.

(3) Há uma série de dificuldades que se impõe ao pesquisador que se arvora à busca por interpretações de dinâmicas do passado, uma delas está vinculada à disponibilidade de fundos com documentação que lance luz aos eventos pretéritos. O exercício dessa busca é um verdadeiro "garimpo" documental e um trabalho típico do pesquisador da Geografia Histórica.

(4) A pesquisa em arquivos por vezes apresenta verdadeiros "hiatos" de documentação. São encruzilhadas da pesquisa em que a lacuna de dados históricos obscurece olhares interpretativos sobre os fatos espaciais. Alternativas a esta situação está na busca por outras fontes e no entendimento de que a ausência de dados não significa o vazio de ocupação, mas outra lógica territorial não mapeada pelos agentes hegemônicos.

(5) A cartografia histórica é definitivamente um instrumento habitual e essencial aos estudos de Geografia Histórica, visto que apresenta uma perspectiva interpretativa (de quem fez o mapa) sobre as configurações espaciais de um determinado tempo e espaço. Deve-se ter a clareza, entretanto, que a dinâmica territorial é muito mais complexa que as possibilidades de um mapa, sendo esse uma mera representação escalar de alguns componentes fixos selecionados para serem mostrados.

(6) A Geografia Histórica como campo do saber e o patrimônio como elemento social (material ou imaterial) selecionado sob determinados critérios podem, ambos, articulados, se apresentarem como instrumento de resistência, ao passo que possibilitam a ativação popular do patrimônio-territorial com o resgate e visibilização de práticas e grupos de agentes omitidos pela historiografia oficial.

(7) De outra forma, pode-se afirmar que é possível vislumbrar outras e novas histórias a partir da apreensão de dinâmicas territoriais passadas. Não é tarefa fácil, exige grande rigor metodológico e analítico para não sucumbir ao desejo de simplesmente dizer algo novo sem um embasamento na pesquisa primária, sendo que esta, via de regra, foi produzida por agentes hegemônicos. Ou seja, é a busca por documentação escrita, cartográfica, iconográfica e oral que possibilita lançar olhares interpretativos a grupos e espaços que têm pouca presença na documentação oficial, porquanto, carecem de um protagonismo na escrita da história, visto que a possuem na existência e na produção do território.

(8) Esses aspectos anteriormente apresentados dão margem para a proposta pensada e sugerida por Costa (2017) de ativar patrimôniosterritoriais por e a partir da periferia. A Geografia Histórica possibilita o recontar da história do território com a identificação dos agentes de produção do espaço, analisando os seus interesses e articulações e permitindo o entendimento de (i)lógicas que se impõem ao território de hoje, mas que refletem estruturas socioespaciais de tempos bem mais recuados.

$\mathrm{Na}$ construção dessas elaborações teóricometodológicas sobre a Geografia Histórica e a ativação popular do patrimônio-territorial, há certamente uma série de lacunas que se apresentam como pistas para pesquisas que seguem, a exemplo da discussão sobre as transformações sociais decorrentes da patrimonialização de 
eventos/monumentos populares e o consequente uso turístico do mesmo.

Outra brecha que se apresenta à pesquisa é a relação entre oportunismo econômico, consumo pós-moderno, pós-industrial e a guarda da memória cultural do patrimônio ativado. São duas faces da mesma moeda: a necessidade de ativar o patrimônio-territorial, aqui estruturada ao longo do artigo, e o que decorre dos novos usos que podem se impor a partir dessa ativação.

O pesquisador da Geografia Histórica não pode ser um simples "ventríloquo" de povos e grupos culturais soberanos, porém oprimidos, omitidos e esquecidos na historia até então contada. É necessário dar a esses grupos o protagonismo no contar de novas histórias territoriais sob o risco de impormos a nossa interpretação sobre as suas práticas. Esse entendimento dá à Geografia Histórica o desejado papel de verdadeiras "máquinas de guerra" na revelação de dinâmicas territoriais subversivas.

\section{Referências}

Abreu, M. A. (1994). O Estudo geográfico da cidade no Brasil: evolução e avaliação. Contribuição à história do pensamento geográfico brasileiro. In A. F. A. Carlos (Org.). Os caminhos da reflexão sobre a cidade e o urbano (pp.199-322). São Paulo: EDUSP.

Abreu, M. A. (2000). Construindo uma geografia do passado: Rio de Janeiro, cidade portuária, século XVII. GEOUSP Espaço e Tempo, 4(1), 13-25. Recuperado em 24 outubro, 2020 , http://www.revistas.usp.br/geousp/article $\angle$ view/123400/119716

Abreu, M. A. (2002). Pensando a cidade no Brasil do Passado. In I. E. Castro, P. C. C. Gomes \& R. L. Corrêa (Orgs.) Brasil: questões atuais da reorganização do território (pp.145-184). (2a.ed.). Rio de Janeiro: Bertrand Brasil.

Abreu, M. A.(2005). Reencontrando a antiga cidade de São Sebastião: Mapas conjecturais do Rio de Janeiro do século XVI. Cidades. 2(4), 189-220. São Paulo: Gráfica Provo.

Abreu, M. A. (2011). Sobre a memória das cidades. In A. F. A. Carlos, M. L. Souza \& M. E. B. Sposito (Orgs.). A producão do espaço urbano. Agentes e processos, escalas e desafios (pp.1939). São Paulo: Contexto.
Alvarado-Sizzo, I. (2019). Territorio, memoria e imaginario del trabajo. La hacienda y El ejido colectivo em Nueva Italia, México. PatryTer, 2(3), 08-25. Recuperado em 24 outubro, https://periodicos.unb.br/index.php/patr yter/article/view/23063

Andrade, A. B. (2013). O outro lado da Baía. A gênese de uma rede urbana colonial. Salvador: EDUFBA.

Andrade, A. B. \& Andrade, J. J. (2019). Cartografia, dinâmica territorial e patrimônio material: análise a partir do Oeste baiano nos setecentos. PatryTer, 2(3), 49-60. Recuperado em 23 outubro, 2020, https://periodicos.unb.br/index.php/patr yter/article/view/19355

Andrade, A. B. \& Brandão, P. R. B. (2009). Geografia de Salvador. (2a. ed.). Salvador: EDUFBA.

Andrade, A. B., Pinto, F. M. \& Braga, R. R. (2018). Olhares cruzados sobre o "Tempo": uma abordagem interdisciplinar. Revista O Saber, XI (11), pp.54-70. Brasilia: EGGCF.

Araújo, R. M. (2001). A urbanização do Mato Grosso no século XVIII. Tese de Doutorado em História da Arte, Universidade Nova de Lisboa, Lisboa, Portugal.

APEB. (1715). Inventário de Luqia de Araíjo Caldas. Seção Judiciária. Cota: 02 / 634 / 1088 / 07. Salvador, Bahia, Brasil.

Bauzy, F.; Ribeiro, G. (2015). A criação e expansão dos cursos de pós-graduação em Geografia no Brasil: 1971 a 2014. Anais do XV Encontro de Geógrafo da América Latina, Havana, Cuba.

Biblioteca Nacional. (1754). Suite du Bresil: depuis la baye de tous lês Saints jusqu'a St. Paul / Jacques Nicolas Bellin, ARC.010,12,039. Rio de Janeiro, Brasil.

Braudel, F. (1978) Escritos sobre a História [Ed. Francesa, 1969]. São Paulo: Editora Perspectiva.

Corrêa, R. L. (1995). O Espaço Urbano. (3a.ed.). São Paulo: Editora Ática S.A.

Costa, E. B. (2010). A concretude do fenômeno turístico e as cidades-patrimônio-mercadoria: uma abordagem geográfica. Rio de Janeiro: Livre Expressão.

Costa, E. B. (2015). Metodologia para a Geografia Histórica Urbana: depoimentos orais [ou testemunhos] como documentos. Anais do Simpósio Nacional de Geografia Urbana, Fortaleza, CE, Brasil, 14. Recuperado em 20 outubro, 2020, https://drive.google.com/file/d/OB FJH 8ikGCJtU2tmaVU2UkFzaHM/view 
Costa, E. B. (2016). Utopismos patrimoniais pela América Latina: resistências aà colonialidade do poder. Actas del Colóquio Internacional de Geocrítica, Barcelona, Espanha, 14. Recuperado em 20 outubro, 2020,

http://www.ub.edu/geocrit/xiv everaldoc osta.pdf

Costa, E. B. (2017). Ativação popular do patrimônio-territorial na América Latina: teoria e metodologia. Cuadernos de Geografia, 26(2), 53-75. Recuperado em 20 outubro, 2020 ,

http://www.scielo.org.co/pdf/rcdg/v26n 2/0121-215X-rcdg-26-02-00053.pdf

Costa, E. \& Moncada, J. (2021, no prelo). Decolonialidad originaria latinoamericana y condicionamiento barroco del territorio novohispano: conventos, presidios y pueblos de indios. Cuadernos de Geografía: Revista Colombiana de Geografía, $30(1)$.

Exército Português. (pós 1808). Planta do porto $e$ comarca da Babia de Todos os Santos. Reg. $n^{\circ} 8762$, Post 1808.

Hirt, I.\& Lerch, L. (2014). Cartografiar las territorialidades indígenas en los Andes bolivianos: intereses políticos y desafíos metodológicos. Cybergeo: European Journal of Geography, (638), Recuperado em 24 outubro,

2020 ,

https://journals.openedition.org/cybergeo $\angle 26207$

Lemos, A. I. G. (2018). Em busca de uma Geografia Latino-Americana Crítica ou por uma Geografia Mestiça. Boletim Paulista de Geografia, (100), 112-129, Recuperado em 22 outubro, 2020, https://www.agb.org.br/publicacoes/inde x.php/boletim-paulista/article/view/1502

Lepetit, B. (2001). Por uma nova história urbana. São Paulo: EDUSP.

Magnavita, P. R. (2004). Diferente forma de pensar a cidade e o urbanismo. A história e a lógica da multiplicidade. Anais do Seminário da História da Cidade e do Urbano. Niterói, RJ, Brasil, 8.

Maluly, V. S. (2019). Voyages et formation territoriale: une approche cartographique exploratoire du récit d'Auguste de Saint-Hilaire (Brésil, 18161817). Dissertação de Mestrado em Geografia, École dês Hautes Études en Sciences Sociales, Paris, França.
MEC. (2019). A democratização e expansão da educação superior no país (2003-2014). Recuperado em 19 agosto, 2019, http://portal.mec.gov.br/index.php?optio $\mathrm{n}=\mathrm{com}$ docman\&view $=$ download \&alias $=$ 16762-balanco-social-sesu-20032014\&Itemid $=30192$

Moraes, A. C. R. (2002). Território e história no Brasil. São Paulo: Hucitec.

Moraes, A. C. R. (2009). Geografia Histórica do Brasil. Cinco ensaios, uma proposta e uma crítica. São Paulo: Annablume.

Pinheiro, D. J. F. \& Silva, M. A. (2004). Visões imaginárias da cidade da Babia. Salvador: EDUFBA.

Santos, M. (1997). A Natureza do Espaço. Técnica e Tempo. Razãa e Emoção. (2a.ed.). São Paulo: Hucitec.

Santos, M. (2006). Por uma Geografia Existencial. In A. I. G. Lemos, M. L. Silveira \& M. Arroyo (Orgs.). Questões Territoriais na América Latina (pp.19-26). São Paulo: CLACSO.

Santos, M. \& Silveira, M. S. (2001). O Brasil: Território e Sociedade no início do século XXI. Rio de Janeiro: Record.

Vasconcelos, P. A. (1997). Os agentes modeladores das cidades brasileiras no período colonial. In I. E. Castro; P. C. C. Gomes \& R. L. Corrêa (Orgs.). Explorações Geográficas: percursos no fim do século (pp. 247-278). Rio de Janeiro: Bertrand Brasil.

Vasconcelos, P. A. (1999). Questões metodológicas na Geografia Urbana Histórica. In P. A. Vasconcelos \& S. B. M. Silva (Orgs.) Novos Estudos de Geografia Urbana Brasileira (pp. 191-201). Salvador: UFBA.

Vasconcelos, P. A. (2002). Salvador: transformações e permanências (1549-1999). Ilhéus: Editus.

\section{Notas}

i Não obstante a sinalização de cortes orçamentários e diminuição de oferta desde 2017 decorrente da conjuntura política do Brasil (manobra para a sucessão do executivo federal e ascensão da extrema direita), é significativo observar os ganhos substantivos do período de 2003 a 2014, a exemplo do crescimento de 94\% das matrículas em universidades na região Nordeste (p.21) e no aumento do número de cursos de graduação no país de 16.505, em 2003, 
para 32.049, em 2013 (p.23).

ii Mantidas as ressalvas na nota anterior atinentes ao perverso cenário político brasileiro hodierno, na análise que os autores supramencionados fazem dos cursos de pós-graduação stricto-sensu de Geografia os dados são reveladores, a exemplo da expansão de nove ao final da década de 1980 (final do período da ditadura militar), para 84 (55 mestrados e 29 doutorados) em 2014.

iii No uso desse conceito, norteador nas análises desse artigo, acompanha-se o entendimento de Costa $(2017$, p.59) quando indica o patrimônioterritorial como resistência, sendo "elemento de arte, cultura e vivências situadas na periferia, bem material-imaterial ainda em realização espacial no continente (sem qualquer ato de institucionalização por parte do Estado-mercado), ele se opera em singularidade (o fazer do e no lugar) diante de múltiplas particularidades (economias políticas regionais e nacionais), as quais conformam relações sociais de trabalho".

iv Expressão emprestada de Magnavita (2004) para tratar da utilização de instrumentos do saber subversivos ao conhecimento posto, oficialmente historicizado.

v Noção filosófica defendida por Santos (1997, p. 114) e aprofundada na seção sete desse artigo.

vi Conceito desenvolvido por Santos (1997) para tratar do espaço na escala do local, o espaço do "roçar" cotidiano, dos encontros e do nível da vida entre os iguais.

vii Conceito apresentado em Santos (1997) e aqui utilizado para fazer menção à circulação de pessoas, mercadorias e informações que se dava no território do Brasil Colonial num velocidade, volume e precisão bastante lentos se comparados com os fluxos contemporâneos.

viii Milton Santos faz uso desse conceito para tratar de espaços de comando com maior fluidez e interesses das empresas globais, em oposição aos espaços opacos. Para evitar o risco de anacronia, ressalva-se que o uso para tempos mais recuados é feito para indicar os espaços do controle (do mandar) em oposição aos espaços do fazer.

ix Andrade (2013) buscando dados que revelassem as dinâmicas internas do Recôncavo Baiano setecentista, foi encontrar num fundo de Cíveis um documento (APEB, 1715) que apresentava o inventário de herança de uma "preta" alforriada que morava no termo de Cachoeira (principal vila interior do Recôncavo). Nesse documento aparecem diversas informações sobre as posses dessa senhora, como: pretos de ganho, roças de mandioca e casas de aluguel na vila de Cachoeira que dão pistas sobre relações socioespaciais muito mais complexas que as duais campoXcidade ou senhoresXescravos.

x O texto desta seção é um fragmento modificado do artigo "Olhares cruzados sobre o 'Tempo': uma abordagem interdisciplinar" (Andrade, Pinto \& Braga, 2018).

xi Acrônimo utilizado no setor agrícola, notadamente na EMBRAPA (Empresa Brasileira de Pesquisa Agropecuária) para identificar a fronteira de expansão da agropecuária comercial entre os estados do Maranhão, Tocantins, Piauí e Bahia.

xii Acompanha-se aqui o entendimento da Geografia como ciência do presente apresentado de Santos (1997) problematizado por Abreu (2000). 